\title{
Vitamin D reduces Exacerbation in Children with Asthma: A Systematic Review and Meta-analysis
}

\author{
${ }^{1}$ Anil Chauhan, ${ }^{2}$ Manvi Singh, ${ }^{3}$ Nishant Jaiswal, ${ }^{4}$ Kiran Kumar Thumburu, ${ }^{5}$ Amit Agarwal \\ ${ }^{6}$ Shailender Singh Chauhan, ${ }^{7}$ Sunil Dhatwalia, ${ }^{8}$ Mananda S Bhende, ${ }^{9}$ Meenu Singh
}

\begin{abstract}
Aim: The question whether treatment with vitamin $D$ improves asthma exacerbations in children and adults still needs to be addressed.

Background: Recent studies in children and adults found a higher prevalence of hypovitaminosis D associated with a higher severity of asthma and impaired pulmonary function. In asthmatic children, patients with vitamin $D$ deficiency demonstrated increased airway hyperresponsiveness and corticosteroid requirements.
\end{abstract}

Results: Of 469 records/studies identified through database searching, 5 studies were included in this systematic review. The overall pooled effect showed a significant reduction in acute asthma exacerbation in the vitamin $\mathrm{D}$ group (odds ratio 0.45 , $95 \%$ confidence interval 0.22-0.93). There were no studies that focus on the quality of life.

Conclusion: This systematic review supports the role of vitamin $D$ in reducing the number of asthma exacerbations in children but not in adults.

Clinical significance: The present systematic review demonstrates reduction in asthma exacerbations in children. Most of the asthma children are on inhaled corticosteroid, which poses a threat for its side effects. However, vitamin D having multiple functions in body could be used as an alternative therapy in asthmatic children. In adults, more trials are needed wherein the deficient individuals are supplemented with vitamin $\mathrm{D}$ and further assessed for asthma exacerbations. There is no harm in supplementation of vitamin $\mathrm{D}$ to deficient and insufficient asthmatic individuals.

Keywords: Asthma, Exacerbations, Heterogeneity, Placebo, Pulmonary function test, Systematic review, Vitamin D.

How to cite this article: Chauhan A, Singh M, Jaiswal N, Thumburu KK, Agarwal A, Chauhan SS, Dhatwalia S, Bhende MS,

1,3-5,7 Senior Research Officer, ${ }^{2}$ Senior Resident, ${ }^{6}$ Postdoctoral Research Associate, ${ }^{8,9}$ Professor

${ }^{1-5,7,9}$ Department of Pediatrics, ICMR Advanced Centre for Evidence Based Child Health, Postgraduate Institute of Medical Education and Research, Chandigarh, India

${ }^{6}$ Department of Biochemistry and Molecular Biology, College of Medicine, University of Nebraska Medical Center, Omaha Nebraska, USA

${ }^{8}$ Department of Pediatrics, University of Pittsburgh School of Medicine, Pittsburgh, Pennsylvania, USA

Corresponding Author: Meenu Singh, Professor, Department of Pediatrics, ICMR Advanced Centre for Evidence Based Child Health, Postgraduate Institute of Medical Education and Research, Chandigarh, India, Phone: + 01722755620 e-mail: meenusingh4@gmail.com
Singh M. Vitamin D reduces Exacerbation in Children with Asthma: A Systematic Review and Meta-analysis. J Postgrad Med Edu Res 2016;50(2):86-92.

Source of support: The review was supported and funded by ICMR, New Delhi (grant number 5/7/592/11-RHN). The funders had no role in study design, data collection and analysis, decision to publish, or preparation of the manuscript.

Conflict of interest: None

\section{BACKGROUND}

Asthma is a chronic inflammatory airway disease, characterized clinically by wheezing and intermittent dry coughing at night, and confirmed by documenting reversible airflow obstruction or airway hyperresponsiveness. The global prevalence of physician-diagnosed asthma, clinical/ treated asthma, and wheezing in adults was $4.3,4.5$, and $8.6 \%$ respectively, and prevalence vary as much as 21 -fold among the 70 countries. ${ }^{1}$ Vitamin D plays an important role in calcium and bone metabolism as well as immunomodulation. Many cells (brain, colon, prostate, breast, immune cells) contain vitamin D receptors (VDRs) and respond to 1, 25-dihydroxyvitamin $\mathrm{D}$ (the active form of vitamin $\mathrm{D}$ ). ${ }^{2}$ There have been multiple reports of association between vitamin D deficiency and diseases, such as cancer, depression, cardiovascular diseases, diabetes, multiple sclerosis, osteoporosis, fertility, and asthma. ${ }^{3,4}$ There are few studies that show a negative association between vitamin D levels and asthma. ${ }^{4}$ The linkage between VDR polymorphisms on chromosome 12 and the diagnosis of asthma has been reported. ${ }^{3}$

Recent studies in adult and children found a higher prevalence of hypovitaminosis $\mathrm{D}$ in asthmatic individuals than in the normal population. In addition, low vitamin D levels are associated with higher asthma severity and worse pulmonary function. ${ }^{4,5}$ In asthmatic children, patients with vitamin D deficiency demonstrated increased airway hyperresponsiveness and corticosteroid requirements. In asthmatic children and adults, serum 25-hydroxyvitamin D levels less than $30 \mathrm{ng} / \mathrm{ml}$ have been linked to airway hyperresponsiveness, impaired lung function, increased exacerbation frequency, and reduced corticosteroid responsiveness. ${ }^{6-9}$ Vitamin D has been hypothesized to increase glucocorticoid response in patients with asthma. Greater lung function is associated with higher vitamin D levels with a $22.7( \pm 9.3) \mathrm{ml}($ mean $\pm \mathrm{SE})$ increase in forced 
expiratory volume in 1 second (FEV1) for each nanogram per milliliter increase in vitamin $D(p=0.02)$. There is increased airway hyperresponsiveness in participants with vitamin D insufficiency $(<30 \mathrm{ng} / \mathrm{ml})$, with a provocative concentration of methacholine inducing a $20 \%$ fall in FEV1 of $1.03( \pm 0.2) \mathrm{mg} / \mathrm{ml}$ vs $1.92( \pm 0.2)$ $\mathrm{mg} / \mathrm{ml}$ in those with vitamin $\mathrm{D}$ of $30 \mathrm{ng} / \mathrm{ml}$ or higher $(p=0.01){ }^{6,7}$ Although the underlying mechanisms are still unknown, it has been suggested that vitamin D augment anti-inflammatory function of corticosteroids in asthma, either by enhancing the ability of $\mathrm{T}$ cells to produce interleukin (IL)-10 or through inhibition of Th17 cytokine production. ${ }^{10,11}$ Low vitamin D levels also create a proinflammatory state. These findings suggest that vitamin $\mathrm{D}$ supplementation could modify the steroid response and reduce airway inflammation. However, the question whether treatment with vitamin $\mathrm{D}$ improves the outcome in patients with asthma has not been reviewed and still needs to be addressed. ${ }^{10,11}$

\section{RESULTS}

\section{Inclusion Criteria}

The studies included were randomized controlled trials, in which vitamin D supplementation was compared with placebo/no supplementation in patients with asthma (moderateto severe) diagnosed in accordance with Global Initiative for Asthma (GINA) guidelines. The inclusion of studies was not restricted by the dose of vitamin D received, concomitant use of corticosteroids (oral/inhaled) for treatment of asthma, and language of publication.

\section{Objectives of the Study}

The primary objective of the review was to determine the evidence supporting the role of vitamin D in decreasing the number of participants with acute exacerbations. The secondary objectives were improvement in the quality of life questionnaire and adverse events reported to be related to vitamin D supplementation.

\section{Search Methods for identification of Studies}

We attempted to identify all relevant studies, regardless of language or publication status (published, unpublished, in press, on-going). We searched the following databases: PubMed, Ovid, Embase, and Cochrane Central e-Appendix 1.

We also checked reference lists of all primary studies and review articles, and searched for errata or retractions from the included studies. We also manually searched index Medicus, CTRI, and ClinicalTrials.gov for any ongoing studies and snowball mathod for the manual searching.

\section{Selection of Studies}

Two authors independently screened the titles and abstracts of all the potential studies, removed the duplicates and coded them as "retrieve" (potentially eligible) or "do not retrieve" (not eligible). The retrieved full texts were then screened for inclusion and multiple reports/articles, if any, for the same study were collated. The reasons for exclusion of the ineligible studies were recorded. Any disagreements were resolved through discussion with the arbiter.

\section{Data Analysis}

Data were analyzed using RevMan software (version 5.0.2). GRADEpro software developed by Grading of recommendations assessment, development and evaluation (GRADE) working group was used to grade the evidence as low, moderate, or high quality. ${ }^{12}$

Continuous outcomes were presented as mean differences (MDs) with 95\% confidence interval (CI) and dichotomous outcomes were presented as odds ratio (OR) with 95\% CI. A meta-analysis was performed using a fixed-effect model unless there was evidence of heterogeneity (clinical and statistical) of effects across studies. We used Cochrane criteria to assess the risk of bias (quality) in the clinical studies. ${ }^{13}$

Heterogeneity was interpreted based on thresholds as identified in The Cochrane Handbook for Systematic Reviews of Interventions. ${ }^{14}$ We estimated statistical heterogeneity among studies using the chi-square test statistic and in turn used the result to calculate the heterogeneity statistics. ${ }^{14}$ (Prospero registration number: CRD42014013619).

\section{Overview of Included Studies}

Out of 469 records/studies identified through database searching and 14 additional records/studies, through other sources, 133 records were removed as duplicates. The remaining 350 records were screened for titles and abstracts. Nine studies were extracted as full-text articles. Four studies were excluded (two were nonrandomized controlled trials, ${ }^{15,16}$ one was a murine study, ${ }^{17}$ and one reported outcomes not relevant to the inclusion criteria ${ }^{18}$ ). Finally, five studies were included in the systematic review (Flow Chart 1). This systematic review was conducted in accordance with the guidelines of the preferred reporting items for systematic reviews and meta-analysis (PRISMA) statement. ${ }^{19}$ Two review authors independently extracted the data from included studies and noted the characteristics of included studies (Table 1). Risk of bias graph was also prepared for the included studies (Graph 1).

The minimum dose of total cholecalciferol supplemented was 90,000 IU in 24 weeks and maximum 


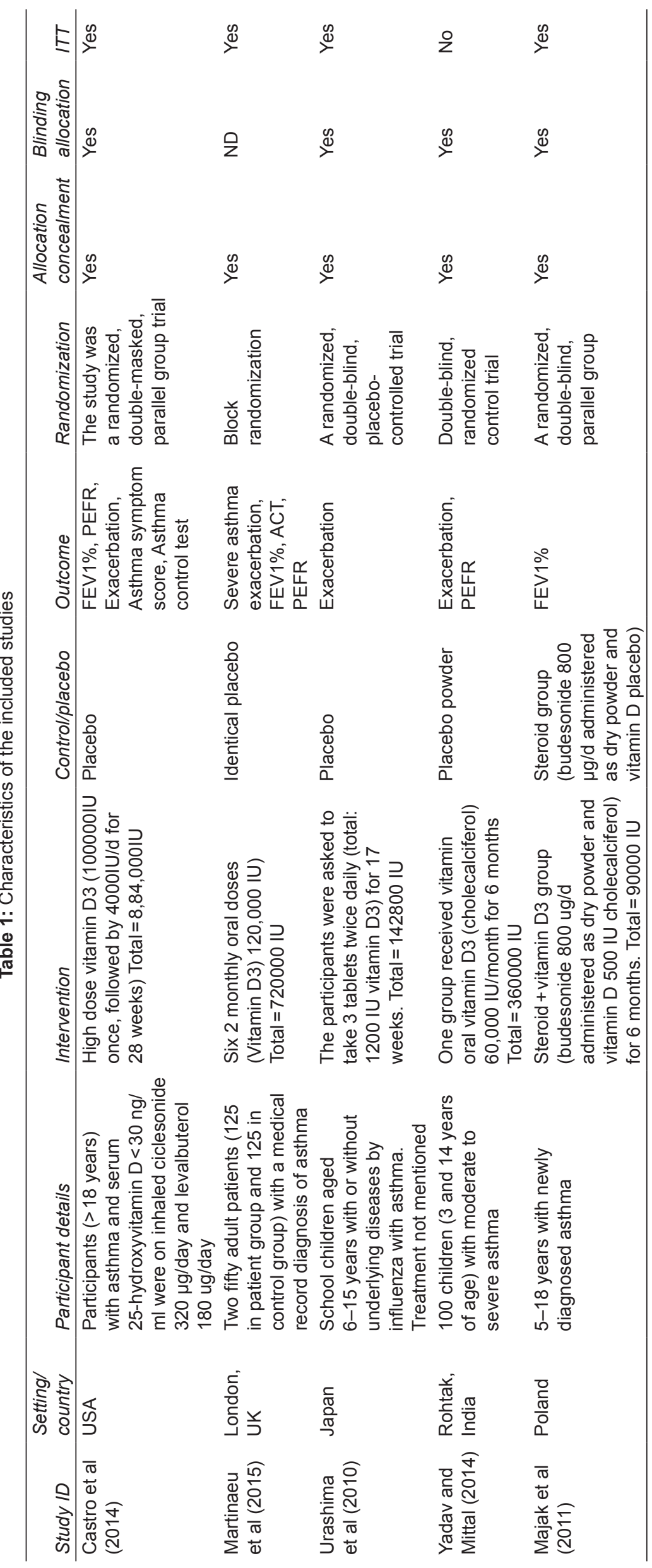


Flow Chart 1: Prisma chart for identifying studies

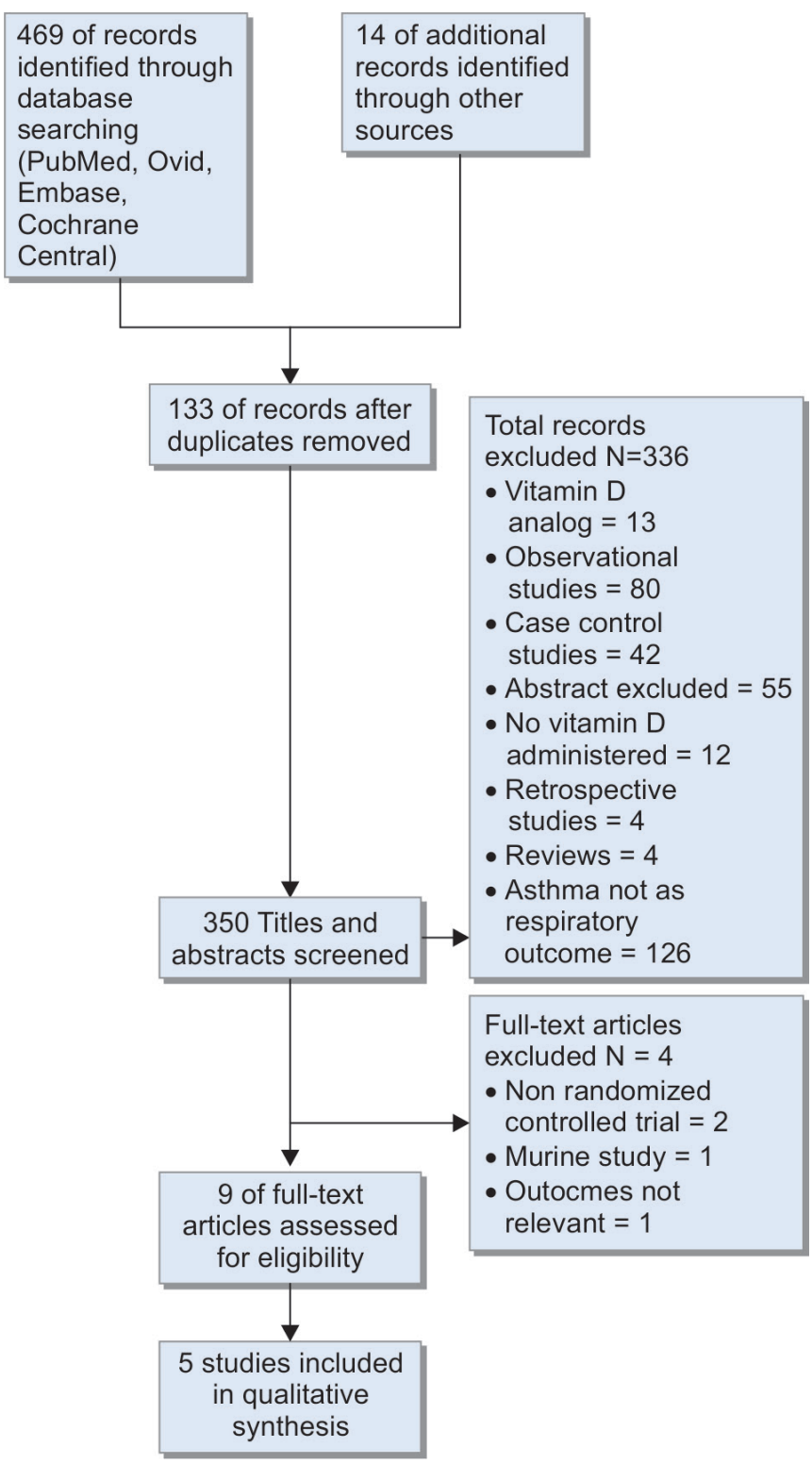

of $8,84,000$ IU for 28 weeks in the included studies. The duration and dose of vitamin D supplementation has been listed in characteristics of included studies (Table 1).

Five studies assessed the number of participants with asthma exacerbations as a primary outcome. ${ }^{20-24}$ In children, three studies had participants less than 18 years of age $(n=482) .{ }^{21-23}$ The number of participants with asthma exacerbations (any severity) in children $(<18$ years of age) was significantly reduced in the vitamin D supplemented group (OR:0.23, 95\% CI:0.12-0.43). In adults ( $>18$ years age), the number of participants with exacerbations was not significantly reduced in the vitamin D supplemented group (OR:0.89, 95\% CI:0.47-1.68) $(n=630) \cdot{ }^{20,24}$ The overall pooled effect showed a significant reduction in number of participants with asthma exacerbation in vitamin D supplemented group (OR:0.45, 95\% CI:0.22-0.93, five trials; moderate-quality evidence; Tables 2 and 3).

There were no studies that reported data on quality of life questionnaire. A total of 23 serious adverse events in 20 participants and 1283 nonserious adverse events in 240 participants were reported by the single study. ${ }^{24}$ The quality of the evidence was assessed according to GRADE using GRADEpro software (Table 3).

\section{DISCUSSION}

\section{Summary of Results}

This systematic review and meta-analysis on the evidence of vitamin D supplementation in patients with moderate to severe asthma has shown its effect on various aspects of asthma. Vitamin D supplementation has significantly reduced the asthma exacerbations in children. ${ }^{21-23}$

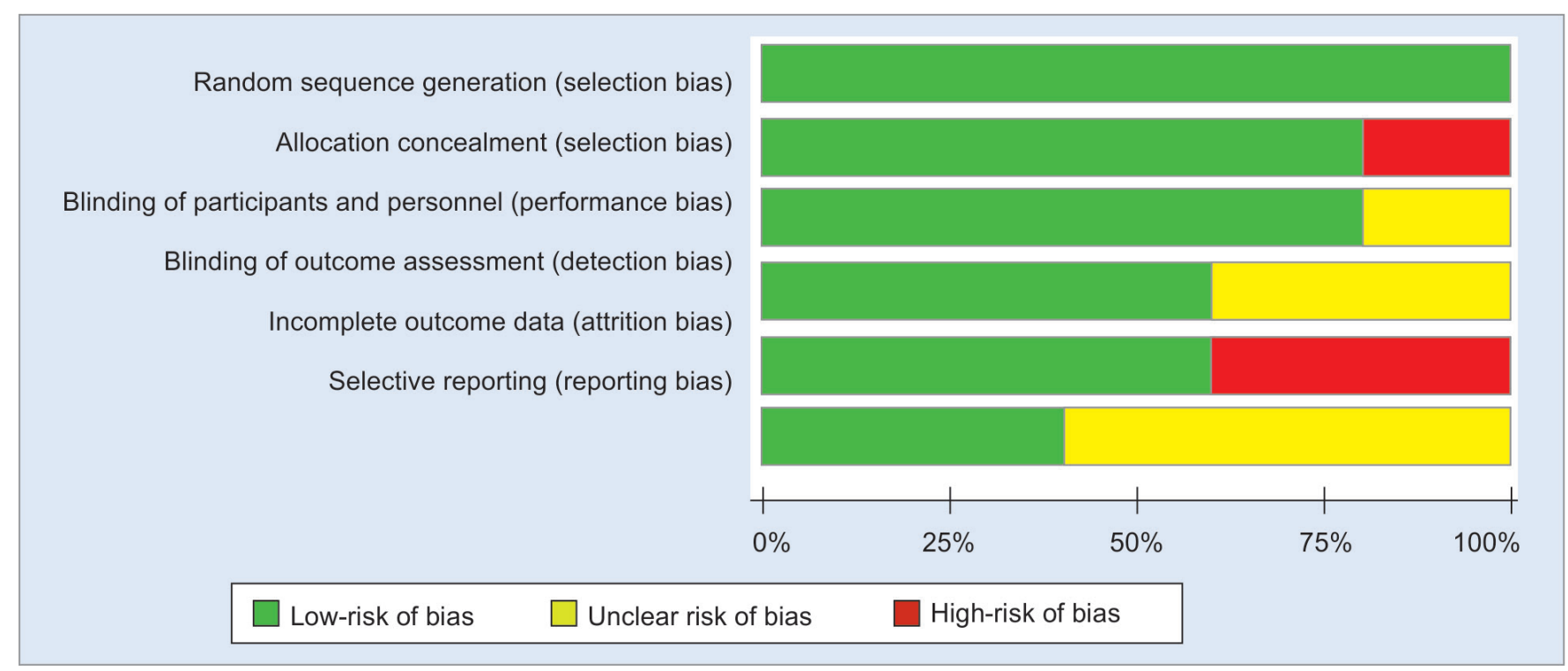

Graph 1: Risk of bias graph 
Table 2: Forest plot of comparison: Vitamin D vs placebo, outcome: Patients with acute exacerbation. Odds ratio relates the ratio of odds of frequency of acute exacerbations in individuals with asthma supplemented with vitamin $\mathrm{D}$ compared with placebo

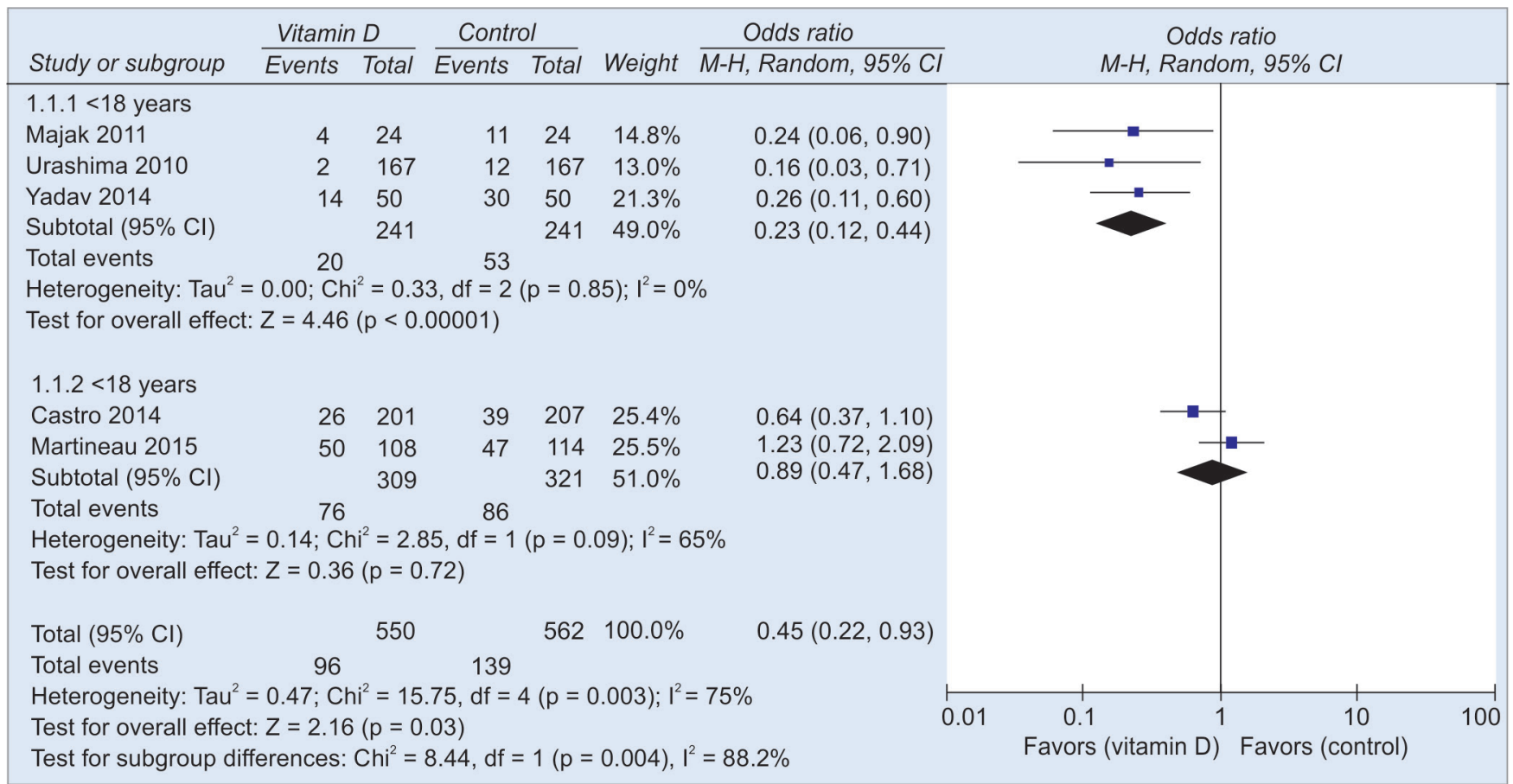

Table 3: Summary of finding table

\begin{tabular}{|c|c|c|c|c|c|}
\hline \multirow[b]{2}{*}{ Outcomes } & \multicolumn{2}{|c|}{ Anticipated absolute effects ${ }^{*}(95 \% \mathrm{Cl})$} & \multirow{2}{*}{$\begin{array}{l}\text { Relative effect } \\
(95 \% \mathrm{Cl})\end{array}$} & \multirow{2}{*}{$\begin{array}{l}\text { No. of participants } \\
\text { (studies) }\end{array}$} & \multirow{2}{*}{$\begin{array}{l}\text { Quality of the } \\
\text { evidence (GRADE) }\end{array}$} \\
\hline & Risk with placebo & Risk with vitamin $D$ & & & \\
\hline \multirow{4}{*}{$\begin{array}{l}\text { Patients with asthma } \\
\text { exacerbation }\end{array}$} & \multicolumn{2}{|c|}{ Study population } & \multirow{4}{*}{$\begin{array}{l}\text { OR } 0.45 \\
(0.22-0.93)\end{array}$} & \multirow[t]{4}{*}{1112 (5 RCTs) } & \multirow{4}{*}{$\begin{array}{l}\oplus \oplus \oplus \mathrm{O} \\
\text { MODERATE }^{1}\end{array}$} \\
\hline & 247 per 1000 & 129 per $1000(67-234)$ & & & \\
\hline & & Moderate & & & \\
\hline & 412 per 1000 & 240 per $1000(134-395)$ & & & \\
\hline \multirow{4}{*}{$\begin{array}{l}\text { Patients with asthma } \\
\text { exacerbation } \leq 18 \\
\text { years }\end{array}$} & Stu & y population & \multirow{4}{*}{$\begin{array}{l}\text { OR } 0.23 \\
(0.12-0.44)\end{array}$} & \multirow[t]{4}{*}{482 (3 RCTs) } & \multirow{4}{*}{$\begin{array}{l}\oplus \oplus \oplus \mathrm{O} \\
\text { MODERATE }^{2}\end{array}$} \\
\hline & 220 per 1000 & 61 per $1000(33-110)$ & & & \\
\hline & & Moderate & & & \\
\hline & 458 per 1000 & 163 per 1000 (92-271) & & & \\
\hline \multirow{4}{*}{$\begin{array}{l}\text { Patients with asthma } \\
\text { exacerbation } \geq 18 \\
\text { years }\end{array}$} & \multicolumn{2}{|c|}{ Study population } & \multirow{4}{*}{$\begin{array}{l}\text { OR } 0.89 \\
(0.47-1.68)\end{array}$} & \multirow[t]{4}{*}{630 (2 RCTs) } & \multirow{4}{*}{$\begin{array}{l}\oplus \oplus \oplus \mathrm{O} \\
\text { MODERATE }\end{array}$} \\
\hline & 268 per 1000 & 246 per $1000(147-381)$ & & & \\
\hline & \multicolumn{2}{|r|}{ Moderate } & & & \\
\hline & 300 per 1000 & 276 per $1000(168-419)$ & & & \\
\hline
\end{tabular}

${ }^{1}$ Urashima et al (2010) and Yadav and Mittal (2014) had attrition bias. Reporting bias was shown by Castro et al (2015) and Martineau et al (2015)

Urashima et al (2010) and Yadav and Mittal (2014) have attrition biases

${ }^{3}$ Reporting bias by Castro et al (2014) and Martineau et al (2015)

However, in adults, two studies ${ }^{20,24}$ did not report any reduction in the number of participants with asthma exacerbations. There were no studies that reported quality of life questionnaire. There were 23 serious adverse events and a total of 1283 nonserious adverse events reported by a single study. ${ }^{24}$

\section{Heterogeneity and Sensitivity Analysis}

Heterogeneity was considerably higher in the trials included to determine asthma exacerbations in those $>18$ years of age. Thus, the sensitivity analysis was done by using the random effect model. The higher heterogeneity was due to a single study done in children, having higher effect size than the other four included studies in children having low effect size (Table 4 ). ${ }^{22}$

The results of our systematic review on asthma exacerbations were similar in comparison to a previous meta-analysis, but a subgroup analysis done in our review is not reported by the previous meta-analysis. ${ }^{25}$ The results of the meta-analysis on exacerbation were not documented by the recent systematic review that included observational studies. ${ }^{26}$ 
Table 4: Sensitivity analysis for the outcome of asthma exacerbation

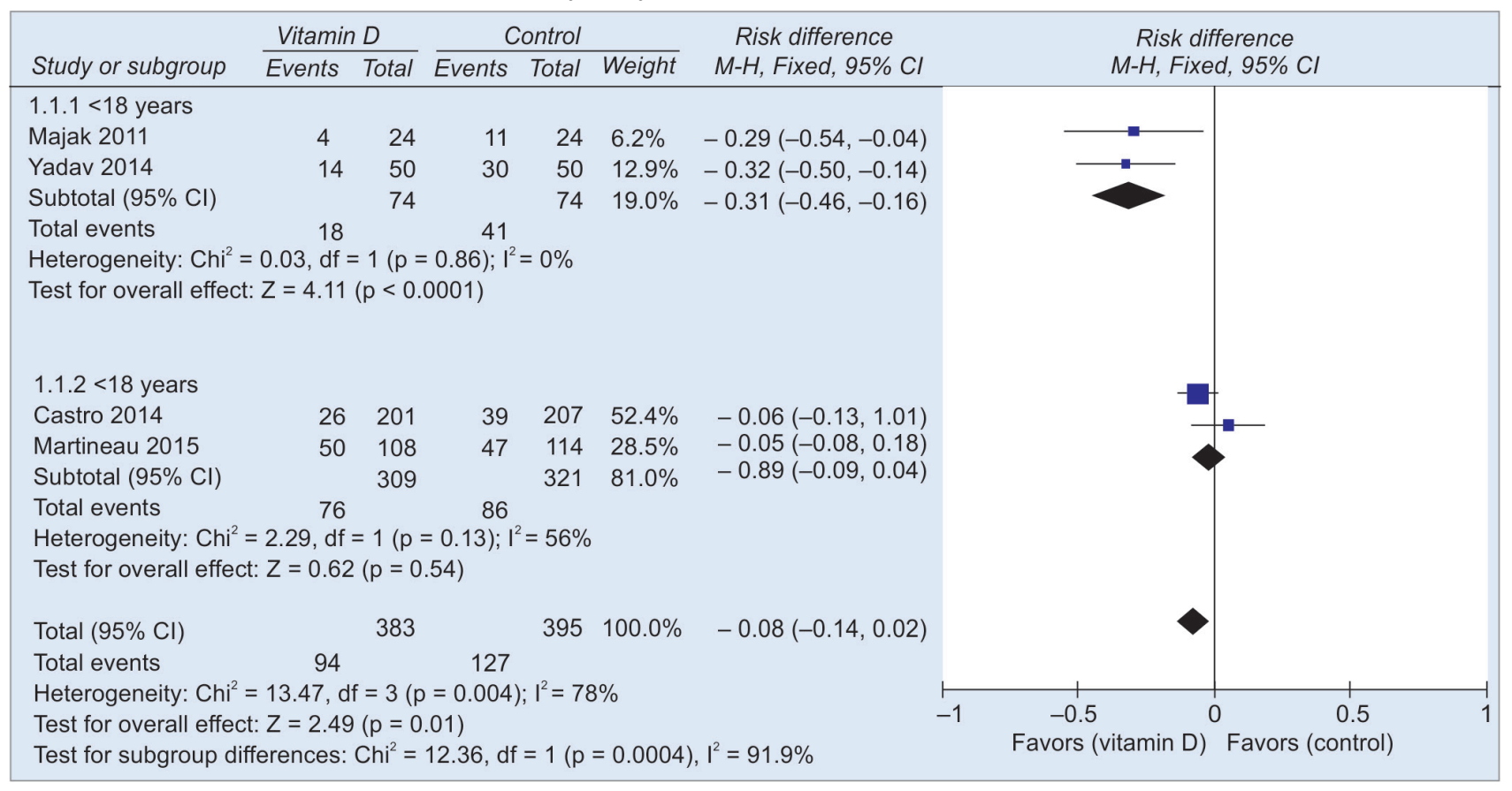

The moderate quality of GRADE reported in our systematic review is due to significant attrition shown by two of the included studies ${ }^{22,23}$ and no description of the method of randomization and allocation concealments in one included study. ${ }^{22}$ The GRADE analysis done in our review is not demonstrated by previous systematic reviews. ${ }^{25,26}$

\section{Strengths and Limitations of Review}

The strength of the present systematic review lies in the inclusion of studies that report the outcomes in both children and adult asthmatic individuals. Our study reported the reduction in number of participants with asthma exacerbations in children, with the similar findings documented by the previous review. ${ }^{27}$ However, there is no reduction in adult population and is not reported by previous review. ${ }^{27}$ There are no studies that focus on the secondary outcome of the quality of life in the included studies. The data from the ongoing trials could not be added due to nondisclosure of results. The pooled sample size of the included trials is low, leading to a higher heterogeneity. Based on the results from our systematic review, it is recommended to design future randomized trials with primarily analyzing baseline levels of vitamin $\mathrm{D}$, and then supplementing with higher doses of vitamin $\mathrm{D}$ for the deficient ones for a fixed duration of time.

\section{CONCLUSION}

This systematic review supports the role of vitamin $D$ in reducing the number of asthma exacerbations in children but not in adults.

\section{ACKNOWLEDGMENT}

The authors would like to the ICMR Advanced Centre for Evidence Based Child Health, Department of Pediatrics, Postgraduate Institute of Medical Education \& Research, Chandigarh, India.

\section{REFERENCES}

1. To T, Stanojevic S, Moores G, Gershon AS, Bateman ED, Cruz AA, Boulet LP. Global asthma prevalence in adults: findings from the cross-sectional world health survey. BMC Public Health 2012 Mar19;12:204.

2. Holick MF. Vitamin D deficiency. N Engl J Med 2007;357:266281.

3. Raby BA, Silverman EK, Lazarus R, Lange C, Kwiatkowski DJ, Weiss ST. Chromosome 12q harbors multiple genetic loci related to asthma and asthma-related phenotypes. Hum Mol Genet 2003 Aug15;12(16):1973-1979.

4. Freishtat RJ, Iqbal SF, Pillai DK, Klein CJ, Ryan LM, Benton AS, Teach SJ. High prevalence of vitamin D deficiency among inner-city African American youth with asthma in Washington, DC. J Pediatr 2010 Jun;156(6):948-952.

5. Brehm JM, Celedon JC, Soto-Quiros ME, Avila L, Hunnighake GM, Forno E, Laskey D, Sylvia JS, Hollis BW, Weiss ST, et al. Serum vitamin D levels and markers of severity of childhood asthma in Costa Rica. Am J Respir Crit Care Med 2009 May1;179(9):765-771.

6. Sutherland ER, Goleva E, Jackson LP, Stevens AD, Leung DY. Vitamin D levels, lung function, and steroid response in adult asthma. Am J Respir Crit Care Med 2010 Apr 1;181(7):699-704.

7. Searing DA, Zhang Y, Murphy JR, Hauk PJ, Goleva E, Leung DY. Decreased serum vitamin D levels in children with asthma are associated with increased corticosteroid use. J Allergy Clin Immunol 2010 May;125(5):995-1000.

8. Wu AC, Tantisira K, Li L, Fuhlbrigge AL, Weiss ST, Litonjua A. Effect of vitamin D and inhaled corticosteroid treatment 
on lung function in children. Am J Respir Crit Care Med 2012 Sep 15;186(6):508-513.

9. Brehm JM, Schuemann B, Fuhlbrigge AL, Hollis BW, Strunck RC, Zeiger RS, Weiss ST, Litonjua AA. Serum vitamin D levels and severe asthma exacerbations in the Childhood Asthma Management Program study. J Allergy Clin Immunol 2010 Jul;126(1):52-58.e5.

10. Xystrakis E, Kusumakar S, Boswell S, Peek E, Urry Z, Richards DF, Adikibi T, Pridgeon C, Dallman M, Loke TK, et al. Reversing the defective induction of IL-10-secreting regulatory $\mathrm{T}$ cells in glucocorticoid-resistant asthma patients. J Clin Invest 2006 Jan;116(1):146-155.

11. Nanzer AM, Chambers ES, Ryanna K, Richards DF, Black C, Timms PM, Martineau AR, Griffiths CJ, Corrigan CJ, Hawrylowicz CM. Enhanced production of IL-17A in patients with severe asthma is inhibited by 1alpha, 25-dihydroxyvitamin D3 in a glucocorticoid-independent fashion. J Allergy Clin Immunol 2013 Aug;132(2):297-304.e3.

12. Dijkers M. Introducing GRADE: a systematic approach to rating evidence in systematic reviews and to guideline development. (2013). KT Update (1)5. Austin, TX: SEDL, Center on Knowledge Translation for Disability and Rehabilitation Research; 2013.

13. Higgins JPT, Green S. Cochrane Handbook for Systematic Reviews of Interventions Version 5.1 [updated March 2011]. Available from: www.cochrane-handbook.org. : The Cochrane Collaboration; 2011.

14. Deeks JJ, Higgins JPT, D.G. A. On behalf of the CSMG. Analyzing data and undertaking meta-analysis. In: Higgins JPT, Green S, editors. Cochrane Handbook for Systematic Reviews of Interventions Version 5.1.0 [updated March 2011]. The Cochrane Collaboration 2011.

15. Chambers ES, Nanzer AM, Richards DF, Ryanna K, Freeman AT, Timms PM, Martineau AR, Griffiths CJ, Corrigan CJ, Hawrylowicz CM. Serum 25-dihydroxyvitamin D levels correlate with CD4(+)Foxp3(+) T-cell numbers in moderate/ severe asthma. J Allergy Clin Immunol 2012 Aug;130(2):542-544.

16. Columbo M, Panettieri RA Jr, Rohr AS. Asthma in the elderly: a study of the role of vitamin D. Allergy Asthma Clin Immunol 2014 Sep 5;10(1):48.

17. Agrawal T, Gupta GK, Agrawal DK. Vitamin D supplementation reduces airway hyperresponsiveness and allergic airway inflammation in a murine model. Clin Exp Allergy 2013 Jun;43(6):672-683.

18. Stelmach I, Olszowiec-Chlebna M, Jerzynska J, Grzelewski $\mathrm{T}$, Stelmach W, Majak P. Inhaled corticosteroids may have a beneficial effect on bone metabolism in newly diagnosed asthmatic children. Pulm Pharmacol Ther 2011 Aug;24(4): 414-420.

19. Moher D, Liberati A, Tetzlaff J, Altman DG. Preferred reporting items for systematic reviews and meta-analyses: the PRISMA statement. PLoS Med 2009;6:e1000097.

20. Castro M, King TS, Kunselman SJ, Cabana MD, Denlinger L, Holguin F, Kazani SD, Moore WC, Moy J, Sorkness CA, et al. Effect of vitamin D3 on asthma treatment failures in adults with symptomatic asthma and lower vitamin D levels: the VIDA randomized clinical trial. JAMA 2014 May;311(20): 2083-2091.

21. Majak P, Olszowiec-Chlebna M, Smejda K, Stelmach I. Vitamin D supplementation in children may prevent asthma exacerbation triggered by acute respiratory infection. J Allergy Clin Immunol 2011 May;127(5):1294-1296.

22. Urashima M, Segawa T, Okazaki M, Kurihara M, Wada Y, Ida H. Randomized trial of vitamin D supplementation to prevent seasonal influenza A in schoolchildren. Am J Clin Nutr 2010 May;91(5):1255-1260.

23. Yadav M, Mittal K. Effect of vitamin D supplementation on moderate to severe bronchial asthma. Indian J Pediatr 2014 Jul;81(7):650-654.

24. Martineau AR, MacLaughlin BD, Hooper RL, Barnes NC, Jolliffe DA, Greiller CL, Kilpin K, McLaughlin D, Fletcher G, Mein CA, et al. Double-blind randomised placebo-controlled trial of bolus-dose vitamin D3 supplementation in adults with asthma (ViDiAs). Thorax 2015 May;70(5):451-457.

25. Pojsupap S, Iliriani K, Sampaio TZ, O'Hearn K, Kovesi T, Menon K, McNally JD. Efficacy of high-dose vitamin D in pediatric asthma: a systematic review and meta-analysis. J Asthma 2015 May;52(4):382-390.

26. Zhang LL, Gong J, Liu CT. Vitamin D with asthma and COPD: not a false hope? A systematic review and meta-analysis. Genet Mol Res 2014 Feb13;13(3):7607-7616.

27. Riverin BD, Maguire JL, Li P. Vitamin D supplementation for childhood asthma: a systematic review and meta-analysis. PLoS One 2015 Aug31;10(8):e0136841. 